\title{
A study of spectrum and fetomaternal outcome of Jaundice in pregnant women: an experience from a tertiary referral centre of North India
}

\author{
Monica Agrawal, Meenakshi Bhanu, Pushpa Lata Sankhwar*, Sujata Deo, S. P. Jaiswar
}

Department of Obstetrics and Gynecology, King George's Medical University, Lucknow, Uttar Pradesh, India

Received: 08 June 2019

Accepted: 15 June 2019

\section{*Correspondence:}

Dr. Pushpa Lata Sankhwar,

E-mail: sankhwar_pushpa@yahoo.com

Copyright: (c) the author(s), publisher and licensee Medip Academy. This is an open-access article distributed under the terms of the Creative Commons Attribution Non-Commercial License, which permits unrestricted non-commercial use, distribution, and reproduction in any medium, provided the original work is properly cited.

\begin{abstract}
Background: Pregnancy in jaundice is an important Medical disorder, commonly seen in developing countries like India. The objective of the study was to evaluate the causes leading to jaundice in pregnancy and to analyse the fetomaternal outcome in patients of jaundice in pregnancy.

Methods: This was a prospective observational study of antenatal cases with jaundice admitted in the Department of Obstetrics and Gynecology, King Georges Medical University, Lucknow over a period of one year after getting approval of ethical clearance. Total 122 cases were enrolled after informed consent.

Results: Total of 122 cases were enrolled, Incidence of jaundice in pregnancy was $1.2 \%$. Majority of patients were of age group $20-25$ years $48.4 \%$. About $69.7 \%$ presented at gestational age of 29-40 weeks. Most common cause was pre-eclampsia $33.6 \%$, followed by cholestasis $23.75 \%$ and hepatitis $17.2 \%$. Amongst hepatitis, most common was hepatitis B in $26.7 \%$. Out of 122 cases, $59.8 \%$ delivered while $50.2 \%$ were undelivered $52.4 \%$ patients improved and were discharged while $47.6 \%$ patients expired. Vaginal deliveries were $56.1 \%$, abdominal deliveries were $43.9 \%$, and main reason for maternal mortality was hepatic encephalopathy in $64.6 \%$. Mortality was higher in patients with total bilirubin $>10 \mathrm{mg} \%$. Perinatal mortality was $37 \%$.

Conclusions: Pregnancy complicated with jaundice carries very poor maternal and fetal outcome. Poor outcome may be attributed to delay in seeking medical advice, lack of awareness, lack of proper antenatal checkups 100\% ANC booking can help in reducing fetomaternal morbidity and mortality.
\end{abstract}

Keywords: Hepatic encephalopathy, Jaundice, Pregnancy, Preeclampsia, Viral hepatitis, Viral markers

\section{INTRODUCTION}

Liver disorders complicate up to $3 \%$ of all pregnancies. ${ }^{1}$ It could be peculiar to pregnancy like hyperemesis gravidarum, acute fatty liver of pregnancy, cholestasis of pregnancy, hemolysis, elevated liver enzymes, and a low platelet count (HELLP) syndrome and jaundice complicating hypertensive disorders of pregnancy. These conditions usually remit spontaneously in the puerperium. It can be unrelated to pregnancy in patients of infective causes like viral hepatitis and malaria, gall stones, certain drugs or pregnancy in patients of chronic liver diseases. Abnormal liver function tests may be found in 3-5\% of pregnancies with many potential causes including coincidental liver disease and underlying chronic liver disease. ${ }^{1}$

Incidence of jaundice in pregnancy varies greatly worldwide. In developed countries the incidence is around $0.1 \%$ whilst in developing countries it can be range from $3-20 \%$ or higher. ${ }^{2}$

In India the incidence of jaundice in pregnancy is found to be $0.4-0.9 / 1000 .^{3}$ Jaundice in pregnancy carries a grave 
prognosis for both fetus and mother. It is responsible for about $60 \%$ of perinatal mortality and $14 \%$ of maternal mortality. ${ }^{3}$

Viral hepatitis is the most common cause of jaundice during pregnancy. ${ }^{4}$ The course of most viral hepatitis infections (e.g., hepatitis A, B, C and D) is unaltered by pregnancy. However, a more severe course of viral hepatitis in pregnancy has been noted in patients with hepatitis $\mathrm{E}$ and disseminated herpes simplex virus (HSV) infections. ${ }^{5,6}$ Hepatitis E, usually a benign hepatitis infection in men and non pregnant women, acquires a grave form in pregnant women. The incidence of fulminant hepatic failure and mortality rate is much higher than that associated with other hepatic viral infections. $^{7}$

It is the most common hepatotrophic virus associated with fulminant hepatic failure (FHF). ${ }^{8}$ Approximately, $30 \%$ cases of HEV may manifest as FHF with mean maternal mortality of $21.4 \%$, highest being reported from the developing countries. ${ }^{9-11}$

Jaundice in pregnancy appears to be most common in the third trimester. This could be directly attributable to the impairment of the liver to excrete the conjugated bilirubin in the third trimester. ${ }^{12}$ Jaundice is associated with increased fetal morbidity and mortality, particularly from chrionic placental insufficiency, preterm labour fetal distress and intrauterine fetal demise. ${ }^{13}$ An understanding of disease complications can help to formulate effective strategies for disease prevention, control and patients management leading to better fetomaternal outcome. People have moderate knowledge on jaundice, especially very low knowledge over complications and types of jaundice, which has to be improved through adequate education from antenatal period itself. ${ }^{14}$

\section{METHODS}

The prospective observational study on 122 antenatal cases with jaundice admitted at Department of obstetrics and gynecology, King George's Medical University, Lucknow from over a period of one year (August 2016 to July 2017) after getting approval of ethical clearance.

The aim of the study was to know about incidence of jaundice at our hospital, and its effect on fetomaternal outcome. In this study total 122 cases were enrolled after informed consent.

\section{Inclusion criteria}

- All antenatal women booked or unbooked presenting with clinical or laboratory evidence of jaundice

- Patients giving consent.

\section{Exclusion criteria}

- Patient not giving consent
A detailed history of patients illness including origin, duration and progress of following symptoms like yellow coloured urine, anorexia, nausea, vomiting, fever, epigastric pain and pain in abdomen, constipation /diarrhoea, irritability, weakness. Thorough general, systemic and obstetrical examination was done.

Every patient was investigated by routine $\mathrm{CBC}$ and $\mathrm{PBF}$ for haemoglobin, total and different WBC count, platelet counts, blood group, TSH, Blood sugar, Blood urea, HIV, VDRL, malaria. Urine examination was carried out for presence of albumin, sugar, bile salts, bile pigments, urobilinogen and microscopical abnormalities, LFT including SGOT, SGPT, alkaline phosphatase, Prothombin time (PT), partial thromboplastin time (PTT), BT and CT were done Serological tests for viral markersIgManti-HAV antibody, HBV (HBsAg, HbeAg, IgM anti HBV core antigen), IgM anti-HCV antibody and IgM anti-HEV antibody were done.

\section{Statistical analysis}

The results are presented in frequencies, percentages and mean \pm SD. The Chi-square test was used to find the association between categorical variables. The sensitivity, specificity, positive predictive value (PPV), negative predictive value (NPV) and accuracy Swede score was calculated in predicting the HPV. The $p$-value $<0.05$ was considered significant. All the analysis was carried out on SPSS 16.0 version (Chicago,Inc., USA).

\section{RESULTS}

A total of 122 antenatal women with jaundice were included in the study giving an incidence of 12 cases /1000 deliveries $(1.2 \%)$.

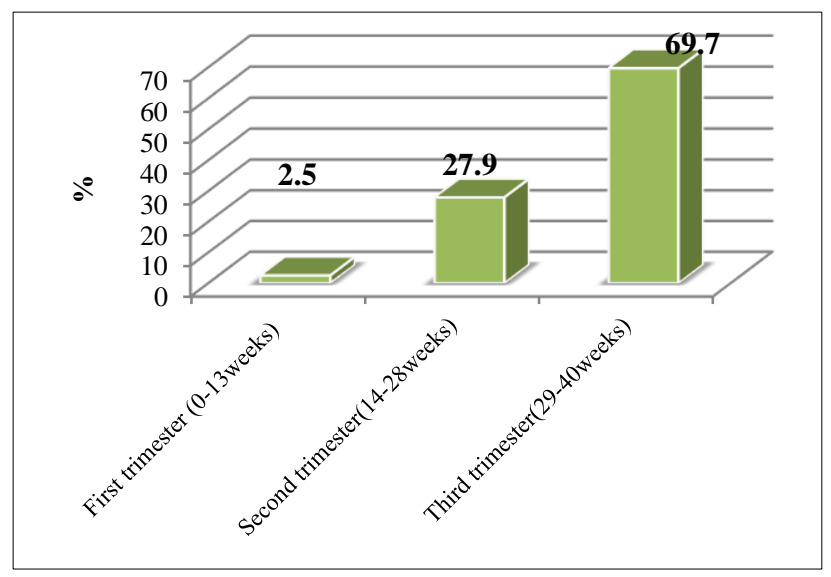

Figure 1: Distribution of jaundice cases according to gestational age.

Majority of patients were of age group 20-25 years (48.4\%) (Table 1). Maximum cases were found to be unbooked $(73.8 \%)$, and of low socioeconomic status $(50.81 \%)$. In this study incidence of jaundice in pregnancy were highest in multigravida i.e. $52 \%$. Most of 
cases had gestational age between $29-40$ weeks $(69.7 \%)$ followed by $14-28$ weeks $(27.9 \%)$ and $0-13(2.5 \%)$ weeks (Figure 1). Majority of cases were seen in $3^{\text {rd }}$ trimester of pregnancy.

Table 1: Distribution of jaundice cases according to age.

\begin{tabular}{|lll|}
\hline Age in years & No. $(\mathrm{n}=122)$ & $\%$ \\
\hline $20-25$ & 59 & 48.4 \\
\hline $26-30$ & 35 & 28.7 \\
\hline$>30$ & 28 & 23.0 \\
\hline Mean \pm SD (Range) & $27.07 \pm 5.07(20-38)$ & \\
\hline
\end{tabular}

\section{Causes of jaundice in pregnancy}

Preeclampsia was the most common cause (50.0\%) followed by Cholestatsis of pregnancy (23.75), Hepatitis $(17.2 \%)$ and Acute fatty liver disease $(9.1 \%)$ (Figure 2). Out of total 122 cases, $16.4 \%$ cases of preeclampsia had HELLP syndrome.

Table 2: Distribution of jaundice cases according to hepatitis.

\begin{tabular}{|lll|}
\hline Hepatitis & No. $(\mathbf{n}=\mathbf{2 1})$ & $\%$ \\
\hline HAV positive & 2 & 9.5 \\
\hline HCV positive & 3 & 14.3 \\
\hline HEV positive & 6 & 28.6 \\
\hline HBsAg positive & 10 & 47.6 \\
\hline HDV & 0 & 0.0 \\
\hline
\end{tabular}

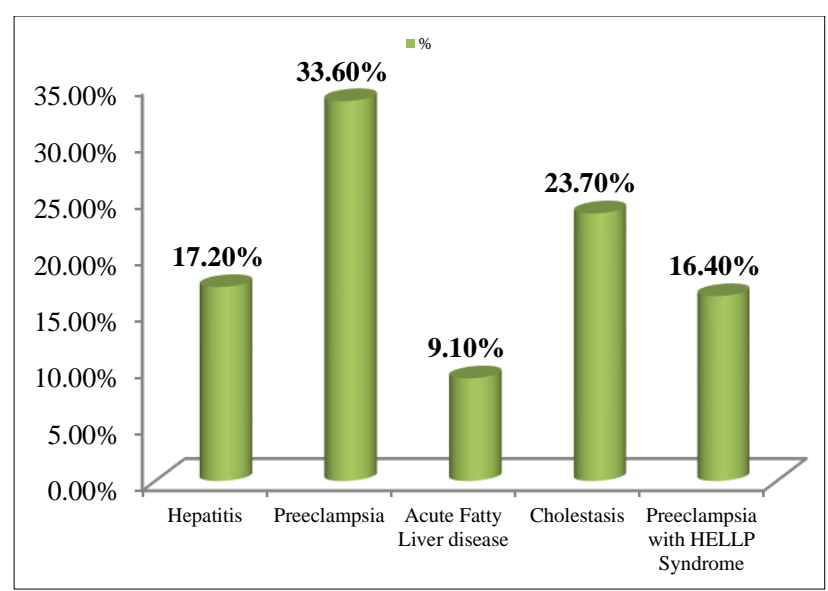

Figure 2: Distribution of jaundice cases according to cause.

In our study $\mathrm{HBV}$ is the most common cause of acute hepatitis comprises $47.6 \% \mathrm{HEV}$ was positive in $28.6 \% \%$ of cases. However, HCV and HAV were positive in $14.3 \%$ and $9.5 \%$ of cases respectively (Table 2). $35.3 \%$ case show bilirubin level less than $10 \mathrm{mg} / \mathrm{dl}$ and $64.7 \%$ showed bilirubin more than $10 \mathrm{mg} / \mathrm{dl}$.

According to LFT, more than half of cases had SGOT $100-500(59 \%)$ followed by $<100(24.6 \%)$ and $>1000$ $(9.8 \%)$ and 501-1000 (6.6\%). However, SGPT was 100500 among $52.5 \%$ cases and $<100$ in $23 \%$ of cases. ALP was between 100-500 among about half of the cases $(49.1 \%$ ) (Table 3). PT and INR were abnormal in $45.9 \%$ cases.

Table 3: Distribution of jaundice cases according to Bilirubin level, SGOT, SGPT and ALP (n=122).

\begin{tabular}{|c|c|c|c|c|c|c|c|c|}
\hline \multirow[t]{2}{*}{ Bilirubin total (mg/dl) } & \multicolumn{2}{|c|}{ No. $(n=122)$} & \multirow[t]{2}{*}{$\begin{array}{l}\text { Bilirubin direct } \\
\text { (mg/dl) }\end{array}$} & \multicolumn{2}{|c|}{ N-104 } & \multirow[t]{2}{*}{$\begin{array}{l}\text { Bilirubin } \\
\text { indirect }\end{array}$} & \multicolumn{2}{|c|}{$\mathrm{N}=18$} \\
\hline & No & $\%$ & & No & $\%$ & & No & $\%$ \\
\hline $0-5$ & 8 & 6.6 & $0-5$ & 5 & 4.8 & $0-5$ & 3 & 16.7 \\
\hline $5-10$ & 35 & 28.7 & $5-10$ & 30 & 28.8 & $5-10$ & 5 & 27.8 \\
\hline $10-15$ & 62 & 50.8 & $10-15$ & 54 & 51.9 & $10-15$ & 8 & 44.4 \\
\hline $15-20$ & 17 & 13.9 & $15-20$ & 15 & 14.4 & $15-20$ & 2 & 11.1 \\
\hline \multirow[t]{2}{*}{ SGOT } & & & SGPT & & & ALP & & \\
\hline & No. & $\%$ & & No. & $\%$ & & No. & $\%$ \\
\hline$<100$ & 30 & 24.6 & $<100$ & 28 & 23.0 & $<100$ & 14 & 11.5 \\
\hline $100-500$ & 72 & 59.0 & $100-500$ & 64 & 52.5 & $100-500$ & 60 & 49.2 \\
\hline $501-1000$ & 8 & 6.6 & $501-1000$ & 9 & 7.4 & $501-1000$ & 18 & 14.8 \\
\hline$>1000$ & 12 & 9.8 & $>1000$ & 21 & 17.1 & $>1000$ & 30 & 24.6 \\
\hline
\end{tabular}

\section{Obstetrical outcome}

According to mode of delivery, among 122 cases: 73 were delivered and 49 were undelivered. Out of the total 73 patients delivered $56.1 \%$ cases had vaginal deliveries and $43.9 \%$ had abdominal deliveries. Among vaginal deliveries, 9 were preterm vaginal deliveries, 26 were full term vaginal deliveries and 6 were instrumental vaginal deliveries. Among abdominal deliveries, 20 were preterm, and 12 were term. The caesareans done were mainly due to fetal distress and instrumental deliveries were performed in unconscious patients in $2^{\text {nd }}$ stage of labour. This higher rate of abdominal deliveries could be 
attributed to early intervention to improve the perinatal outcome. According to labor, labor at point of meeting was present in $49.8 \%$ patients. Spontaneous labor was present in $32.8 \%$ patients and labor was induced in $27 \%$ patients. Among delivered 73 cases, 10 patients were transferred to MICU for further management. Out of these 10 patients, 6 were improved and discharged, 2 expired at MICU, 2 went LAMA and both of them expired at home.
Among undelivered 49 cases, 2 patients went LAMA both expired at home. 4 patients were transferred to MICU, out of which 3 expired and 1 went LAMA who expired at home (Table 4). Out of 122 cases, 64 patients were improved and discharged in satisfactory condition. Fifty eight cases expired, out of which 48 expired at our hospital, 4 seriously ill delivered patients ( 2 in MICU, 2 at home) and 6 undelivered patients expired (3 in MICU and 3 at home).

Table 4: Distribution of jaundice cases according to maternal outcome.

\begin{tabular}{|llllll|}
\hline Delivered & $(\mathbf{n}=\mathbf{7 3})$ & $\%$ & Undelivered & $(\mathbf{n}=49)$ & $\%$ \\
\hline Improved discharge & 50 & 68.5 & Improved discharge & 8 & 16.3 \\
\hline Expired & $\mathbf{1 3}$ & 17.8 & Expired & $\mathbf{3 5}$ & 71.4 \\
\hline Transfer to MICU & 10 & 13.7 & Transfer to MICU & 4 & 8.2 \\
\hline LAMA & 0 & 0.0 & LAMA & 2 & 4.1 \\
\hline
\end{tabular}

Table 5: Comparison of maternal mortality with causes of jaundice.

\begin{tabular}{|c|c|c|c|c|c|c|}
\hline \multirow{3}{*}{ Causes } & \multirow{3}{*}{ No. of cases } & \multicolumn{4}{|c|}{ Maternal mortality } & \multirow{3}{*}{ p-value ${ }^{1}$} \\
\hline & & \multicolumn{2}{|l|}{ Expired } & \multicolumn{2}{|c|}{ Alive } & \\
\hline & & No. & $\%$ & No. & $\%$ & \\
\hline Hepatitis & 21 & 10 & 47.6 & 11 & 52.4 & \multirow{4}{*}{$0.01 *$} \\
\hline Preeclampsia & 41 & 8 & 19.5 & 33 & 80.5 & \\
\hline Obstructive jaundice & 40 & 21 & 52.5 & 19 & 47.5 & \\
\hline HELLP syndrome & 20 & 9 & 45.0 & 11 & 55.0 & \\
\hline
\end{tabular}

${ }^{1}$ Chi-square test, *Significant

Table 6: Comparison of maternal mortality with Bilirubin total, SGOT, SGPT and ALP.

\begin{tabular}{|c|c|c|c|c|c|c|}
\hline \multirow{3}{*}{ Bilirubin total } & \multirow{3}{*}{ No. of cases } & \multicolumn{4}{|c|}{ Maternal mortality } & \multirow{3}{*}{ p-value ${ }^{1}$} \\
\hline & & \multicolumn{2}{|c|}{ Expired } & \multicolumn{2}{|c|}{ Alive } & \\
\hline & & No. & $\%$ & No. & $\%$ & \\
\hline $0-5$ & 8 & 0 & 0.0 & 8 & 100.0 & \multirow{4}{*}{$0.0001 *$} \\
\hline $5-10$ & 35 & 6 & 17.1 & 29 & 82.9 & \\
\hline $10-15$ & 62 & 37 & 59.7 & 25 & 40.3 & \\
\hline $15-20$ & 17 & 5 & 29.4 & 12 & 70.6 & \\
\hline \multicolumn{7}{|l|}{ SGOT } \\
\hline$<100$ & 30 & 0 & 0.0 & 30 & 100.0 & - \\
\hline $100-500$ & 72 & 0 & 0.0 & 72 & 100.0 & \\
\hline $501-1000$ & 8 & 0 & 0.0 & 8 & 100.0 & \\
\hline$>1000$ & 12 & 2 & 16.7 & 10 & 83.3 & \\
\hline \multicolumn{7}{|l|}{ SGPT } \\
\hline$<100$ & 28 & 0 & 0.0 & 28 & 100.0 & - \\
\hline $100-500$ & 64 & 0 & 0.0 & 64 & 100.0 & \\
\hline $501-1000$ & 9 & 2 & 22.2 & 6 & 66.7 & \\
\hline$>1000$ & 21 & 12 & 57.1 & 9 & 42.9 & \\
\hline \multicolumn{7}{|l|}{ ALP } \\
\hline$<100$ & 14 & 0 & 0.0 & 14 & 100.0 & - \\
\hline $100-500$ & 60 & 0 & 0.0 & 60 & 100.0 & \\
\hline $501-1000$ & 18 & 8 & 44.4 & 10 & 55.6 & \\
\hline$>1000$ & 30 & 22 & 73.3 & 8 & 26.7 & \\
\hline
\end{tabular}

${ }^{1}$ Chi-square test, $*$ Significant 


\section{Cause of death}

Total hospital maternal mortality was 39.3\%. Hepatic encephalopathy was the main reason for death $(64.6 \%)$ followed by MODS (10.4\%), HELLP + DIC (10.4\%), $\mathrm{PPH}(8.3 \%)$ and least is septicemia (6.3\%) (Figure 3). On comparison of maternal mortality with causes of jaundice, the percentage of mortality was higher in hepatitis cases $(47.6 \%)$ and was least in preeclampsia cases (19.5\%). (Table 5) On comparison of maternal mortality with total bilirubin, the percentage of maternal mortality was higher among those who had total bilirubin $10-15(59.7 \%)$. It was observed thatthe percentage of mortality was $16.7 \%$ when SGOT was $>1000$ while there was no mortality when SGOT was $<1000$, the percentage of mortality was higher among those who had SGPT $>1000(57.1 \%)$ than 501-1000 (22.2\%). Also the percentage of mortality was higher among those who had ALP levels>1000 (73.3\%) (Table 6).

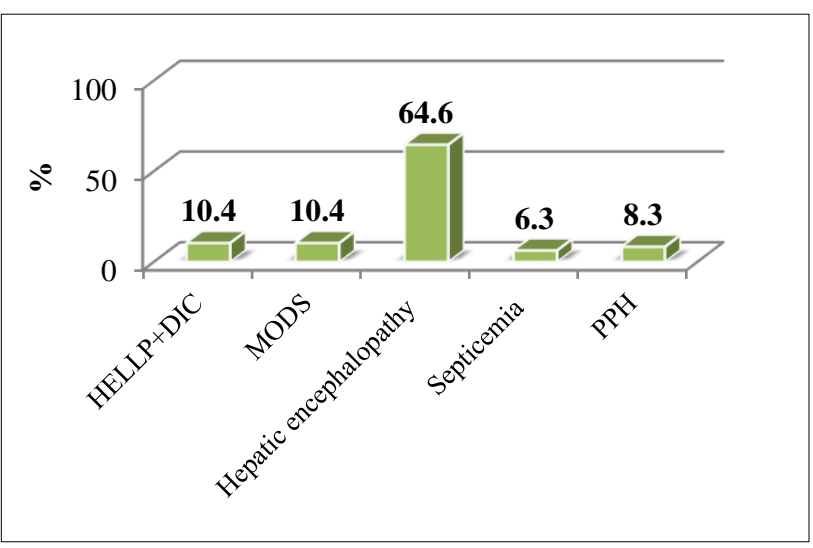

Figure 3: Distribution of jaundice cases according to causes of mortality.

Table 7: Distribution of neonatal outcome in cases of jaundice in pregnancy.

\begin{tabular}{|lll|}
\hline Neonatal outcome & No. $(n=73)$ & $\%$ \\
\hline Discharge healthy & 46 & 63.0 \\
\hline Still birth & 20 & 27.4 \\
\hline Early neonatal death & 7 & 9.6 \\
\hline
\end{tabular}

\section{Perinatal outcome}

In this study we observed that out of 73 delivered cases $63 \%$ babies were health yet the time of discharge, $27.4 \%$ were stillborn and $9.6 \%$ had early neonatal death (Table 7). Total perinatal mortality 37\%. NNU and NICU admission was in $56.3 \%$ and $43.8 \%$ respectively.

\section{DISCUSSION}

Jaundice in pregnancy carries a grave prognosis for both fetus and mother. A total of 122 antenatal women with jaundice were included in the study. Incidence-12 cases/1000 deliveries (1.2\%). Comparable results were reported for incidence of jaundice in pregnancy. In this study, it was found that the incidence of jaundice in pregnancy was highest in cases of age group 20-25 years $(48.4 \%)$. It may be due the fact that higher number of pregnancies were in this age group. Comparable to the results as cited by Nagaria $\mathrm{T}$ et al, who observed maximum incidence of jaundice in 20-30 years that is $89.02 \%$, Karegoudar D et al, found that maximum incidence of jaundice in patients of age group 21-30 years that is $75.68 \% .^{3,19}$ However, Reddy MG et al, found that maximum incidence of jaundice in pregnancy in age group $15-20$ years that is $50 \% .^{20}$

In our study, majority of the cases were unbooked $(73.8 \%)$ and had their first antenatal visit during labour. This is due to lack of awareness about antenatal checkups, low socioeconomic status and poor accessibility to health care centre. Similar results were cited by Nagaria T et al, $(80.55 \%)$ Karegoudar D et al, (56.76\%) and Singh K et al, (75.14\%) cases. ${ }^{3,19,21}$

In this study incidence of jaundice in pregnancy was highest in multigravida i.e., $52 \%$. Mitta $\mathrm{P}$ et al, also noted that majority of causes were multigravida $61.9 \% .^{22}$ Conversely, Singh K et al, and Sharma S et al, noted that $66.6 \%$ of cases were primigravida. ${ }^{21,23}$

In our study, more than half of cases had gestational age between 29-40 weeks (69.7\%). Majority of case were seen in 3rd trimester of pregnancy because majority of liver disease which are unique to pregnancy develop in between 34-37 weeks of the gestation.

Similar findings were observed by Nagaria $\mathrm{T}$ et al, $95 \%$ cases, Reddy MG et al, $80.39 \%$ casesand Mitta $\mathrm{P}$ et al, $83.33 \%$ cases. $^{3,20,22}$ Sharma $\mathrm{R}$ et al, observed all cases were in $3^{\text {rd }}$ trimester. ${ }^{23}$

In our study most common cause of jaundice was preeclampsia, this may be due the fact that, incidence of preeclampsia is more at our hospital, but the rise in bilirubin was not so high in these cases( bilirubin level< $10 \mathrm{mg} \%$ ), therefore the outcome was better in these cases. Similar observations were observed by Choudhary $\mathrm{N}$ et al, according to which preeclampsia and HELLP syndrome were observed in $46.55 \%$ cases. $^{24}$

In our study HBV was the most common cause of acute hepatitis comprising $47.6 \%$ and $\mathrm{HEV}$ was positive in $28.6 \%$ of cases.

According to LFT more than half of cases had SGOT 100-500 (59\%), SGPT was 100-500 among 52.5\% cases, ALP was between 100-500 among about half of the cases $(49.1 \%)$. High levels of SGPT, SGOT, were associated with viral hepatitis and had poor outcome leading to increase in maternal mortality. Mitta $\mathrm{P}$ et al, also found that high level of S. Bilirubin, SGPT and SGOT levels more than $500 \mathrm{IU} / \mathrm{ml}$ were associated with viral hepatitis. $^{22}$ 
In our study, $64.7 \%$ showed bilirubin more than $10 \mathrm{mg} / \mathrm{dl}$. Higher the bilirubin values, poorer was the outcome. Due to this fact we had higher number of morbidity and mortality. Reddy MG et al, observed S. bilirubin level more than $10 \mathrm{mg} / \mathrm{dl}$ present in $44.4 \%$ cases. ${ }^{22}$ Conversely, Karegoudar et al, observed that $67.5 \%$ of cases had bilirubin level less than $10 \mathrm{mg} / \mathrm{dl}$, this variation in observation of other studies could be due to difference in etiological and geographical distribution. ${ }^{19}$

In our study among 122 cases 73 were delivered and 49 were undelivered. LSCS were (32) $43.9 \%$ and vaginal deliveries were (41) $56.1 \%$. Nagaria $\mathrm{T}$ et al, have reported vaginal delivery in 58\% and cesarean section was done in $28 \% .^{3}$ Patel BJ et al, observed that $91.8 \%$ patient delivered, out of which $82.2 \%$ delivered vaginally while $17.7 \%$ were delivered by LSCS. $^{26}$

\section{Maternal outcome}

In our study, hepatic encephalopathy was the main reason for maternal death $(64.6 \%)$ followed by MODS (10.4\%), HELLP+DIC (10.4\%), PPH (8.3\%) and septicemia $(6.3 \%)$. Singh et al, in their study also found that hepatic encephalopathy was the commonest cause $(33.33 \%)$ followed by DIC $(25 \%)$ and sepsis $(25 \%){ }^{21}$ While in other researches various other reasons were predominantly seen like, Satia MN et al, noted that the incidence of DIC (44\%) was high in their study followed by postpartum hemorrhage $(22 \%)$ and hepatic encephalopathy (20\%) Reddy $\mathrm{MG}$ et al, noted that maternal mortality was most common in women with acute fatty liver of pregnancy and HELLP syndrome. ${ }^{20,25}$ Mitta $\mathrm{P}$ et al, noted that the common maternal complications were DIC $11.9 \%$, renal failure $7.14 \%$, abruption, atonic PPH were $4.76 \% .^{22}$ The percentage of mortality was higher in hepatitis cases $(80 \%)$ and was least in preeclampsia cases $(19.5 \%)$.

The percentage of mortality was $16.7 \%$ among whom SGOT was $>1000,57.1 \%$ with SGPT $>1000,73.3 \%$ ALP $>1000,59.7 \%$ with total bilirubin $10-15 \mathrm{mg} \%$.

According to neonatal outcome we observed that out of 73 delivered cases $63 \%$ babies were discharged healthy, $27.4 \%$ were stillborn and $9.6 \%$ had early neonatal death. Total perinatal mortality was $37 \%$. Higher perinatal mortality was also reported by Nagaria T et al, $61.76 \%$ with $50 \%$ stillbirth and $11.76 \%$ early neonatal death. ${ }^{3}$ Perinatal mortality as cited by Acharya $\mathrm{N}$ et al was $16.6 \%$, Karegoudar D et al, $46.16 \%$, Jayanthi et al $19 \%$ and Mitta $\mathrm{P}$ et al $30.76 \% .^{15,18,19,22}$ Reddy MG et al, reported perinatal mortality of $33.3 \% .^{22}$ Jayanti $\mathrm{K}$ et al reported that perinatal mortality was $35.5 \%$ of these $80 \%$ was due to prematurity. ${ }^{18}$ So, we can say that our perinatal mortality was less, due to early intervention in form of abdominal deliveries.

Our NNU and NICU admissions were in $56.3 \%$ and $43.8 \%$ respectively Karegoudar D et al, observed that
$13.51 \%$ required NICU admission. ${ }^{19}$ Jayanthi et al, observed that $66.6 \%$ babies required NICU admission with low birth weight and meconium aspiration syndrome being the most common indications. ${ }^{18}$

Emergence of new contributing factors and constant researches with expanding medical knowledge have a scope for better management and in reducing the morbidity and mortality in mother as well as fetus. Previous research findings did not explore much about epidemiological studies in relation of jaundice with pregnancy from Indian subcontinent.

Therefore, authors planned to execute this study to assess the incidence of jaundice in pregnancy and its effect on fetomaternal outcome.

\section{CONCLUSION}

Though jaundice affects a small percentage of pregnant women, it carries very poor maternal and fetal outcome. Poor outcome may be attributed to delay in seeking medical advice, lack of awareness, low socioeconomic status, lack of proper antenatal checkups leading to delay in early diagnosis and management, delay in referral to the hospital. $100 \%$ ANC booking, routine antenatal screening for hepatitis B and proper regular checkups can reduce the burden of this disease and can help reducing feto-maternal morbidity and mortality. A female admitted with jaundice must be considered high risk and timely management must be given by a trained group of doctors (multidisciplinary approach) Timely referral and transport facilities, adequately trained medical and paramedical staff, availability of blood banks and ventilatory support, good NICU set up can improve the maternal and fetal outcome.

Funding: No funding sources Conflict of interest: None declared

Ethical approval: The study was approved by the Institutional Ethics Committee

\section{REFERENCES}

1. Guntupalli SR, Steingrub J. Hepatic disease and pregnancy: an overview of diagnosis and management. Crit Care Med. 2005;33:332-9.

2. Zakim D, Boyer TD. Hepatology: A Textbook of Liver Diseases. 4th ed. Saunders, Philadelphia; 2003.

3. Nagaria T, Agarwal S, Fetomaternal outcome in jaundice during pregnancy. J Obstet Gynecol India. 2005;55(5):424-7.

4. Knight M, Nelson-Piercy C, Kurinczuk JJ, Spark P, Brocklehurst P. A prospective national study of acute fatty liver of preganancy in the UK. Gut. 2008;57:951-6.

5. Sebire NJ, Jolly M, Harris JP. Maternal obesity and pregnancy outcome: a study of 287,213 pregnancies in London. Int $\mathrm{J}$ Obes Relat Metab Disord. 2001;25:1175-82. 
6. Ibdah JA. Acute fatty liver of preganancy: an update on pathogenesis and clinical implications. World $\mathrm{J}$ Gastroenterol. 2006;12:7397-404.

7. Chung CL, Morgan M, Hainsworth I, Kingham JG. Prospective study of liver dysfunction in pregnancy in Southwest Wales. Gut. 2002;51:876-80.

8. Shalimar, Acharya SK. Hepatitis E and acute liver failure in pregnancy. J Clin Exp Hepatol. 2013;3:213-24.

9. Singh S, Mohanty A, Joshi YK, Dwivedi SN, Deka D. Outcome of Hepatitis E virus infection in Indian pregnant women admitted to a tertiary care hospital. Indian J Med Res. 2001;113:35-9.

10. Mjahed K, Charra B, Hamoudi D, Noun M, Barrou L. Acute fatty liver of pregnancy. Arch Gynecol Obstet. 2006;274:349-53.

11. Reyes H. Review: intraheptic cholestasis. A puzzling disorder of preganacy. J Gastroenterol Hepatol. 1997;12:211-6.

12. Arrese M. Cholestasis during pregnancy: rare hepatic diseases unmasked by pregnancy. Anm Hepatol. 2006;5:216-8.

13. Paus TC, Schneider G, van DE Vondel $P$, Sauerbruch T, Reichel C. Diagnosis and therapy of intrahepatic cholestasis of pregnancy. Z Gastroenterol. 2004;42:623-8.

14. Reyes H, Sjovall J. Bile acids and progesterone metabolites in intrahepatic cholestasis of pregnancy. Ann Med. 2000;32:94-106.

15. Acharya SK, Madan K, Dattagupta S, Panda SK. Viral Hepatitis in India. Natl Med $J$ India. 2006;19:203-17.

16. Parveen M, Aabidha, Cherian AG, Paul E, Helan J. Maternal and fetal outcome in pre-eclampsia in a secondary care hospital in South India. J Family Med Prim Care. 2015;4(2):257-60.

17. Ambreen A, Ahmed F, Sheikh E. Jaundice in pregnancy - a clinical study at Fatima Memorial System. Incidence reported of jaundice in pregnancy. J South Asian Federation Obstet Gynaecol. 2015;7:22-5

18. Krishnamoorthy J, Murugesan A. Jaundice during pregnancy, maternal and fetal outcome. Int J Repro Contracep Obstet Gynaecol. 2016;5(8):2541-5.
19. Karegoudar D, Kumar R, Dhirubhai P, Dhital M, Amgain K. A study of liver disorder and its consequences in pregnancy women with jaundice in tertiary care centre in Belgaum, Karnataka, India. IOSR-JDMS. 2014;13:14-8.

20. Reddy MG, Prabhakar GC, Sree V. Maternal and fetal outcome in jaundice complicating pregnancy. J NTR University Health Science. 2014;3:231-3.

21. Singh K, Kumar G, Singh A, Rani A. Outcome and management of antenatal patients with jaundice in tertiary care centre of eastern India: A retrospective study. Int J Res Med Sci. 2015;3(9):2402-4.

22. Mitta P, Rao SV. Fetomaternal outcome in Jaundice complicating pregnancy. IOSR journal of dental and Medical Sciences (IOSR-JDMS). 2016;15:72-6.

23. Sharma S, Aherwar R, Jawade S. Maternal and fetal outcome in Jaundice complicating pregnancy: A prospective study. Int J Reprod Contracept Obstet Gynaecol. 2016;5:1084-7.

24. Choudhary N, Sen S, Varalakshmi K. A prospective study on pregnancy complicated with jaundice with special emphasis on fetomaternal outcome. Int $\mathbf{J}$ Reprod Contracept Obstet Gynaecol. 2017;6:5081-8.

25. Satia MN, Jandhyala M. A study of fetomaternal outcomes in cases of jaundice at a tertiary care centre. Int J Reprod Contracept Obstet Gynecol. 2016;5:2352-7

26. Patel BJ, Thaker RV. Mewada, Study of fetomaternal outcome in patients of jaundice in third trimester of pregnancy. Int $\mathrm{J}$ Reprod Contracept Obstetrics Gynecol. 2015;4(6):1961-4.

Cite this article as: Agrawal M, Bhanu M, Sankhwar PL, Deo S, Jaiswar SP. A study of spectrum and fetomaternal outcome of Jaundice in pregnant women: an experience from a tertiary referral centre of North India. Int J Reprod Contracept Obstet Gynecol 2019;8:2838-44. 